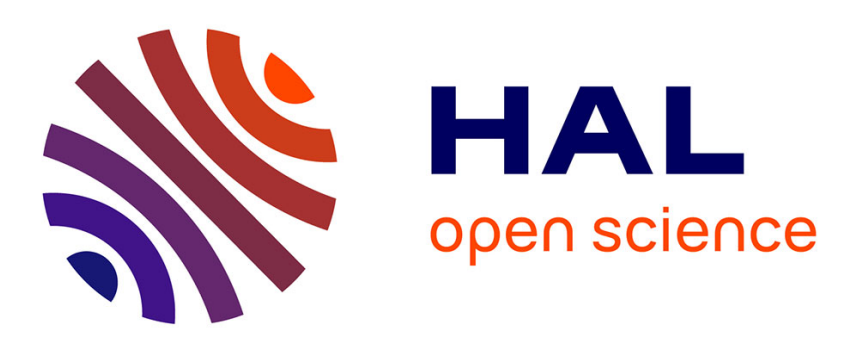

\title{
Towards good quality Bi2ZnB2O7 fibers grown by the micro-pulling down technique
}

\author{
F. Assi, M. Ferriol, M. Cochez, M. Aillerie, B. Ponting, G. Maxwell
}

\section{To cite this version:}

F. Assi, M. Ferriol, M. Cochez, M. Aillerie, B. Ponting, et al.. Towards good quality Bi2ZnB2O7 fibers grown by the micro-pulling down technique. Journal of Crystal Growth, 2016, 451, pp.1-5. 10.1016/j.jcrysgro.2016.06.051 . hal-01338152

\section{HAL Id: hal-01338152 \\ https://hal.univ-lorraine.fr/hal-01338152}

Submitted on 28 Jun 2016

HAL is a multi-disciplinary open access archive for the deposit and dissemination of scientific research documents, whether they are published or not. The documents may come from teaching and research institutions in France or abroad, or from public or private research centers.
L'archive ouverte pluridisciplinaire HAL, est destinée au dépôt et à la diffusion de documents scientifiques de niveau recherche, publiés ou non, émanant des établissements d'enseignement et de recherche français ou étrangers, des laboratoires publics ou privés. 


\title{
Towards good qualityBi $\mathrm{ZnB}_{2} \mathrm{O}_{7}$ crystal fibersgrown
}

\section{bythe micro-pulling down technique}

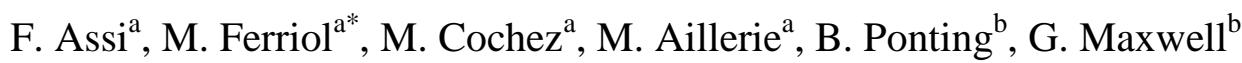 \\ ${ }^{a}$ Université de Lorraine et Centrale-Supélec, LMOPS E.A. 4423, Metz, F-57070, France \\ ${ }^{\mathrm{b}}$ Shasta Crystals Inc., San Francisco, CA, U.S.A.
}

\begin{abstract}
$\underline{\text { Abstract }}$
$\mathrm{Bi}_{2} \mathrm{ZnB}_{2} \mathrm{O}_{7}(\mathrm{BZBO})$ fibers grown by the micro-pulling down technique ( $\mu$-PD) usually present a more or less pronounced color ranging from yellow to red and a microstructure showing glassy clear parts (more concentrated in bismuth) dispersed in a darker matrix. In a previous paper, we assumed a reaction between the platinum crucible and the melt to explain both their color and microstructure. To confirm or invalidate this hypothesis, BZBO fibers were pulled under different conditions by the $\mu$-PD or laser heated pedestal growth(LHPG) techniques. Various physical characterizations methods such as: SEM, EDS microprobe, Raman micro-spectroscopy, DTA and X-ray diffraction were performed to evaluate their crystal quality. Finally, it appears that the origin of the observed features of the fibers grown lies in the evaporation of a substantial amount of boron oxidefrom the melt. This leads to a shift of its composition in the $\mathrm{ZnO}-\mathrm{B}_{2} \mathrm{O}_{3}-\mathrm{Bi}_{2} \mathrm{O}_{3}$ ternary system andan incongruent melting behavior. Therefore, the obtainment of colorless and transparent fibers requires very low pulling rates.
\end{abstract}

Keywords: A1. Characterization; A2.Micro-pulling down technique;A2.Laser heated pedestal growth;B1.Borates; B2.Non-linear optical materials; B2. phosphors

\footnotetext{
* corresponding author tel : +33(0)387939102, fax : +33(0)387939101, e-mail : michel.ferriol@univ-lorraine.fr
} 


\section{Introduction}

Compounds with the formula $\mathrm{X}_{2} \mathrm{YZ}_{2} \mathrm{O}_{7}$ belonging to the melilite structural family offer considerable cation substitution possibilities. Thus, theyare expected to be interesting hosts for various dopants useful for luminescent devices and other applications operating in new wavelength ranges. While the luminescent properties of rare earth ions in several silicate, aluminate or gallatemelilites have been reported [1-3],little researchhas concernedthe borate melilite $\mathrm{Bi}_{2} \mathrm{ZnB}_{2} \mathrm{O}_{7}$ (BZBO) [4, 5]. Discovered by Barbier et al. [6], its structure was found to bea noncentrosymmetric orthorhombic structure,belonging to the $\mathrm{Pba} 2$ space group. According to the literature, it has large nonlinear optical coefficients $\left(\mathrm{d}_{31}=0.91 \mathrm{pm} \mathrm{V}^{-1}\right.$ [7]), a relatively large birefringence $(0.085-0.106$ [8]) and is transparent from $350 \mathrm{~nm}$ (UV cut-off wavelength) to more than $2500 \mathrm{~nm}$ [9]. It is also non-hygroscopicand considered to be a potential competitor for $\mathrm{KDP}\left(\mathrm{KH}_{2} \mathrm{PO}_{4}\right)$ because its doubling efficiency would be three or four times higher $[6,8]$.

The goal of our research was to investigate fiber-shaped BZBO crystals for solid state lasers and optical applications.In a previous paper, we reported on the growth and characterization of BZBO crystal fibers by the micro-pulling down technique ( $\mu$-PD) [10]. The fibers obtained had a uniform color from yellow to orange-red and a microstructurewhich was attributed to the presence of disordered or glassy parts. The origin of the disordered parts was considered to be connected to the presence of a still unidentified Bi-rich phase produced by the reaction of the melt with the platinum crucible. The high viscosity of the melt would impede its total dispersion and dilution resulting in the formation of the colored amorphous zones [10]. The principal objective of this paper was to confirm or disprove these hypotheses and to define the growth conditions allowing the preparation of colorless BZBO single crystal fibers.To this end, BZBO fibers were grown by two techniques: the micro-pulling down method ( $\mu-\mathrm{PD})$ and the laser heated pedestal growth technique (LHPG). 


\section{Experimental}

Powders of stoichiometric BZBO were prepared by solid state reaction of the starting materials: $\mathrm{Bi}_{2} \mathrm{O}_{3}$ (Aldrich 99.99\%), $\mathrm{ZnO}$ (Aldrich 99.99\%) and $\mathrm{H}_{3} \mathrm{BO}_{3}$ (Acros 99.999\%). The detailed procedure is described elsewhere [10].

For the growth of BZBO fibers, the micro-pulling down device installed in our laboratory was used. The growth apparatus and the experimental conditions were described in our previous article [10].Briefly, in the $\mu$-PD method, the material to be grown is molten in a small platinum crucible fitted with a pipe-shaped capillary at its bottom. The fiber is obtained by pulling the seed in the downward direction. Several fibers were also pulled by the cruciblelesslaser heated pedestal growth technique (LHPG) $[11,12]$. In this technique, a $\mathrm{CO}_{2}$ laser beam $(10.6 \mu \mathrm{m})$ is focused onto the end of a ceramic source rod of the material to be grown. When melting is obtained, a seed (single crystal or sintered rod) of smaller diameter than the source rod is dipped into the molten zone, maintained in equilibrium by interfacial tension forces. The fiber crystal is then withdrawn from the molten zone. The source rod is moved into the laser beam in order to feed the molten zone and keep constant its volume. The ratio of pulling and feeding ratesfixes the diameter of the fiber.

The fibersobtained were characterized by differential thermal analysis (DTA), using a Mettler Toledo TGA/SDTA $851^{\mathrm{e}}$ thermal analyzer working with an air gas flow of $20 \mathrm{~cm}^{3} \mathrm{~min}^{-}$ ${ }^{1}$ and with a heating and cooling rate of $10^{\circ} \mathrm{C} \min ^{-1}$. The samples were wrapped in a thin platinum sheet before being placed in the platinum crucibleused to avoid evaporation of volatile components. The measurement accuracy was within $10{ }^{\circ} \mathrm{C}$.

Raman spectroscopy was also used to characterize the crystallinity of BZBO fibers using a micro-spectrometer Horiba-Jobin-Yvon Aramis operating in backscattering geometry with a $785 \mathrm{~nm}$ laser excitation wavelength (spot diameter: $1 \mathrm{~mm}$ and spectral resolution: $1 \mathrm{~cm}^{-}$ 
$\left.{ }^{1}\right)$. Raman spectroscopy is a useful tool to study the crystallinity of a material because the peak width depends on it: the more the peaks broaden, the more the disorder increases and the crystallinity decreases.

SEM investigations were performed with an environmental microscope Fei Quanta Feg 200 (pressure: $150 \mathrm{~Pa}$, acceleration voltage: $15 \mathrm{kV}$ ) fitted with an energy dispersive spectrometer Edax Genesis XM 4i (acceleration voltage: $6 \mathrm{kV}$, emergence angle: $36^{\circ}$ ). The analyses were performed without standards.

High temperature X-ray powder diffraction experiments were carried out with a Philips X'Pert Pro diffractometer equipped with an Anton Parr HTK 1200N furnace accessory. The diffractograms were recorded with $\mathrm{Cu}-\mathrm{K} \alpha$ radiation, between 10 and $75^{\circ}$ in $2-$ theta and in the temperature range 580 and $670^{\circ} \mathrm{C}$. The heating rate was $5^{\circ} \mathrm{C} \mathrm{min}^{-1}$ and the temperature was continuously raised with no time out for recording spectra.

\section{Results and discussion}

\section{1 $\mu-P D$ growth with oxygen or nitrogen flow}

To verify whether the growth atmosphere did or did not influence the color of the fibers, several growth attempts were made using flowing oxygen and nitrogen. Fig. 1 shows typical fibers obtained with a pulling rate of $4.2 \mathrm{~mm} \mathrm{~h}^{-1}$. It can be seen that whichever was used atmosphere, the crystals were always colored and had the same microstructure as fibers previously obtained in an air atmosphere [10]. It was found that the clearest zones were more concentrated in bismuth than boron compared with the darker ones, as shown by EDS microprobe (Fig. 2). 


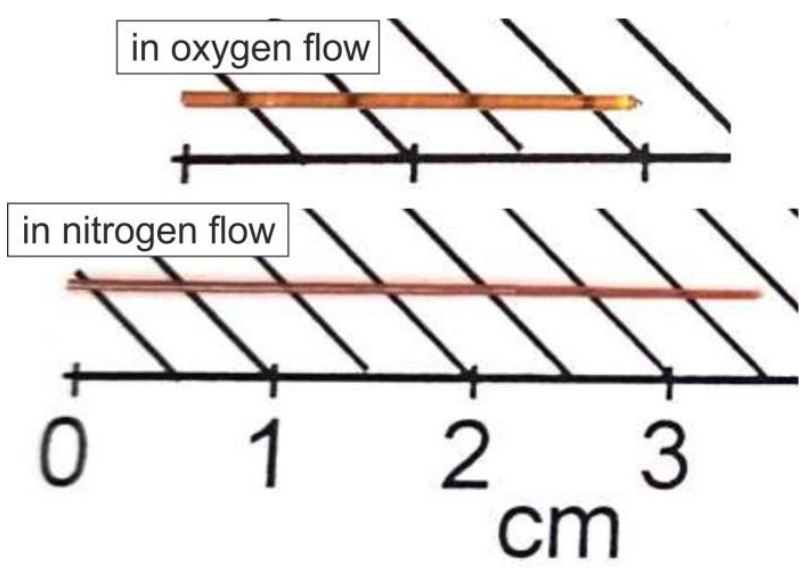

Fig. 1 - BZBO fibers grown by $\mu$-PD (a) in oxygen flowing, (b) in nitrogen flowing
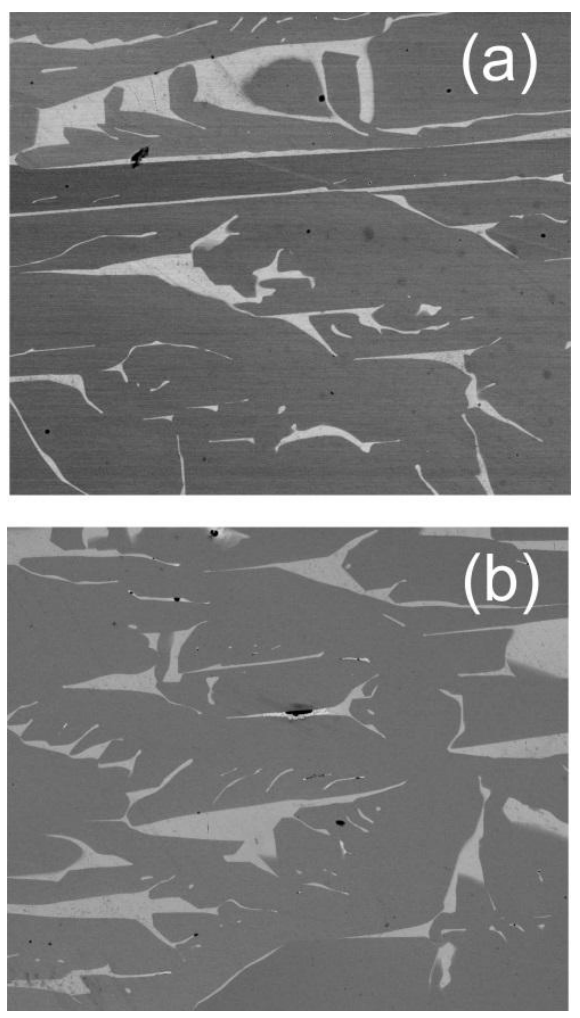

Fig. 2 - SEM images of BZBO fibers grown by $\mu$-PD (a) in oxygen flowing, (b) in nitrogen flowing. The clear zones correspond to a disordered structure according to ref. [10]

\subsection{LHPG experiments}

To confirm or invalidate the existence of a reaction between BZBO melt and platinum crucible, fiber growth was attempted by LHPG. The first trials were performedwith a pulling speed of60 and $120 \mathrm{mmh}^{-1}$ and a feeding speed of $45 \mathrm{mmh}^{-1}$ or higher. A multiphase seed grown by $\mu$-PD with a diameter of about $600 \mu \mathrm{m}$ was used. The ceramic feed rods were cut 
from a sintered pellet of BZBO powder and had a square section with a side between $500 \mu \mathrm{m}$ and $1.2 \mathrm{~mm}$. In all cases, the crystals rapidly separated from the feed rod due to the fact that the required shape stability condition was not satisfied [12]. Only little boules of about three millimeters long could be obtained. However, they were transparent and colorless (Fig. 3(a)). The Raman spectrum inthe vicinity of the surface of a BZBO sample grown by LHPG at high pulling speed (Fig. 3(b)) clearly shows a different shape compared to the spectrum of the surface of a BZBO fiber grown by $\mu$-PD. This shape is the result of the broadening of the Ramanpeaks due to the presence of adisordered structure.The obtainment of this glassy material is due to the higher pulling speeds than those used in $\mu$-PD between 4 and $12 \mathrm{mmh}^{-1}$, high pulling speed being favorable to quenching and vitrification, as it is known that borates easily vitrify.
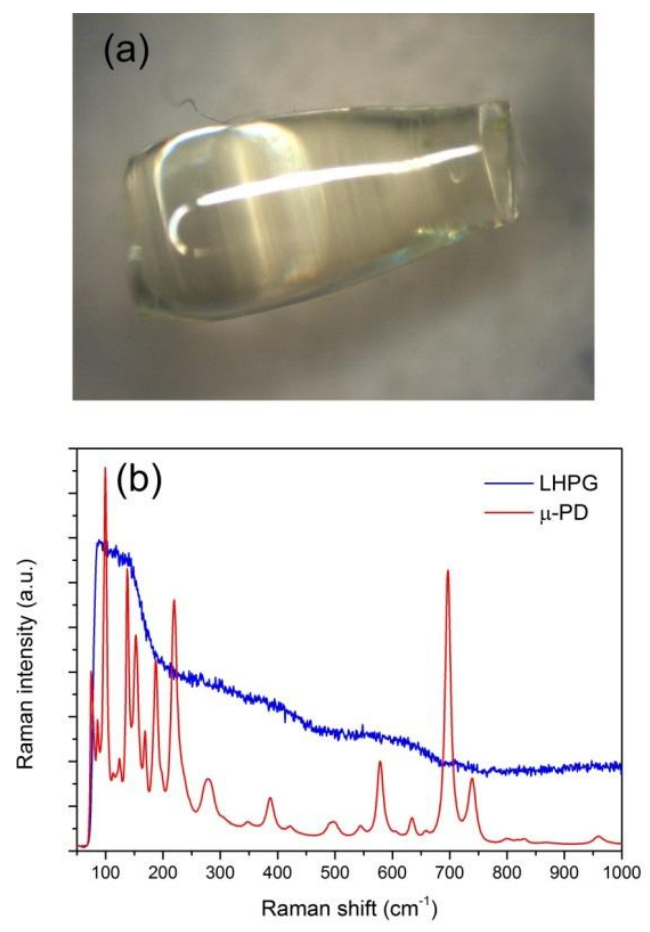

Fig. 3 - (a) BZBO sample grown by LHPG at high pulling speed, (b) Raman spectrum compared to fiber grown by $\mu-\mathrm{PD}$

To avoid as much as possible the glassification, the pulling speed was reduced to 5,10 and $20 \mathrm{~mm} \mathrm{~h}^{-1}$. Several fibers between 10 and $30 \mathrm{~mm}$ long could be grown (Fig. 4(a)). They 
were yellow colored and their Raman spectra corresponded well to that of fibers grown by $\mu-$ PD (Fig. 4(b)) confirming their crystalline structure in the vicinity of the surface. Their microstructure was studied by SEM (Fig. 5). One can see that it is close to that observed for fibers grown by $\mu$-PD [10]: clear zones dispersed in a darker matrix and elongated in the growth axis direction. EDS microprobe confirmed that the clearest zones were more concentrated in bismuth than boron compared with the darker ones. This behavior being identical to that observed for BZBO fibers grown by $\mu-\mathrm{PD}$, it can be concluded that the color and microstructure of the crystals do not originate from a reaction between melt and crucible as previously assumed [10].
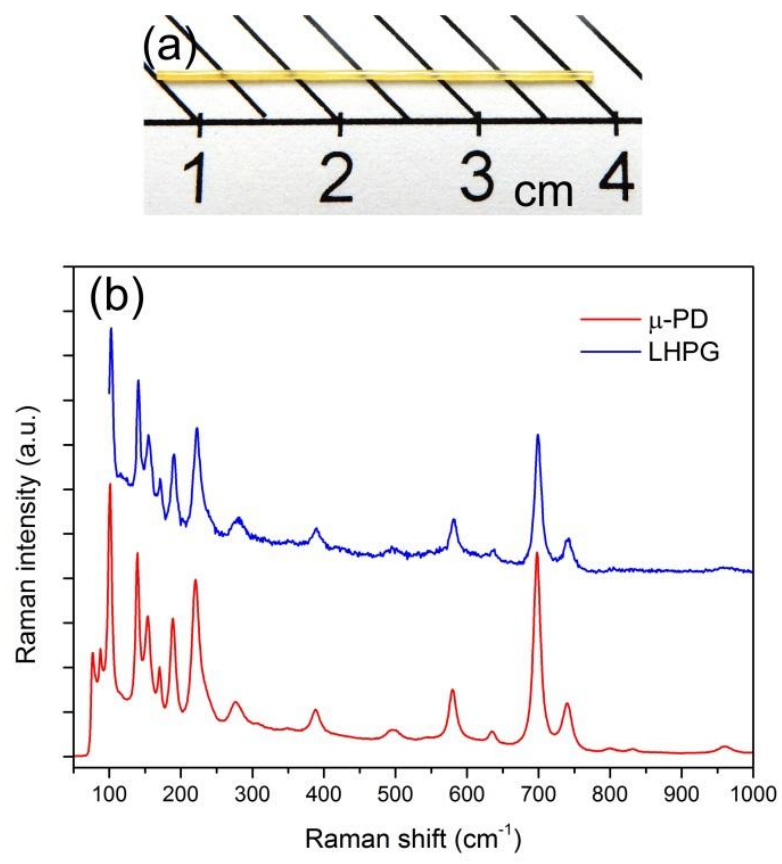

Fig. 4 - (a) Typical BZBO fiber grown by LHPG at low pulling speed, (b) Raman spectrum compared to fiber grown by $\mu$-PD 


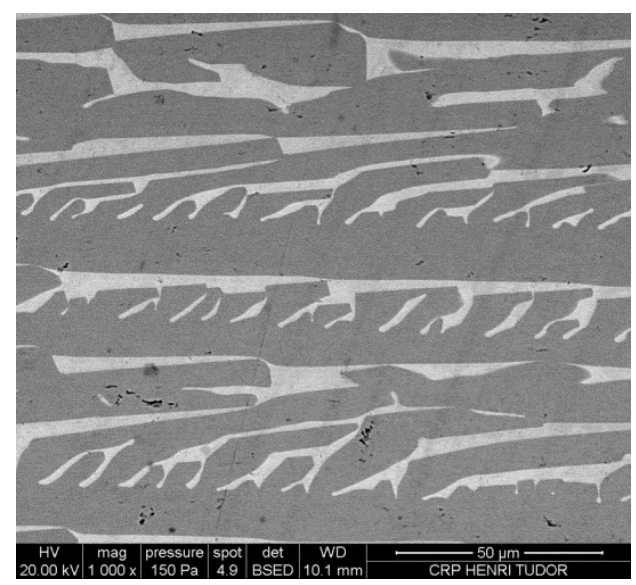

Fig. 5 - SEM image of the microstructure of a BZBO fiber grownby LHPGat low pulling rate

\subsection{Chemical analysis, DTA and high temperature X-ray diffraction experiments}

The elemental analysis of several crushed BZBO fibers was performedby inductively coupled plasma (ICP-AES) after complete mineralization. The results are given in Table 1.

Table 1 - Average elemental analysis of several BZBO crushed fibers

\begin{tabular}{ccc}
\hline Element & mass $\%$ & atom\% \\
\hline $\mathrm{B}$ & 3.08 & 15.42 \\
$\mathrm{Bi}$ & 68.22 & 17.66 \\
$\mathrm{Zn}$ & 10.73 & 8.88 \\
$\mathrm{O}$ & 17.16 & 58.04 \\
\hline
\end{tabular}

Chemical formula : $\mathrm{Bi}_{1.99} \mathrm{Zn}_{1} \mathrm{~B}_{1.74} \mathrm{O}_{6.54}$

It appears that during the growth process, a non-negligible amount of boron oxide probably evaporated mainly from the melt, corresponding to a $\mathrm{B}_{2} \mathrm{O}_{3}$ typical loss of $13.5 \%$ (molar composition). The DTA trace of these crushed fibers is shown in Fig. 6. 

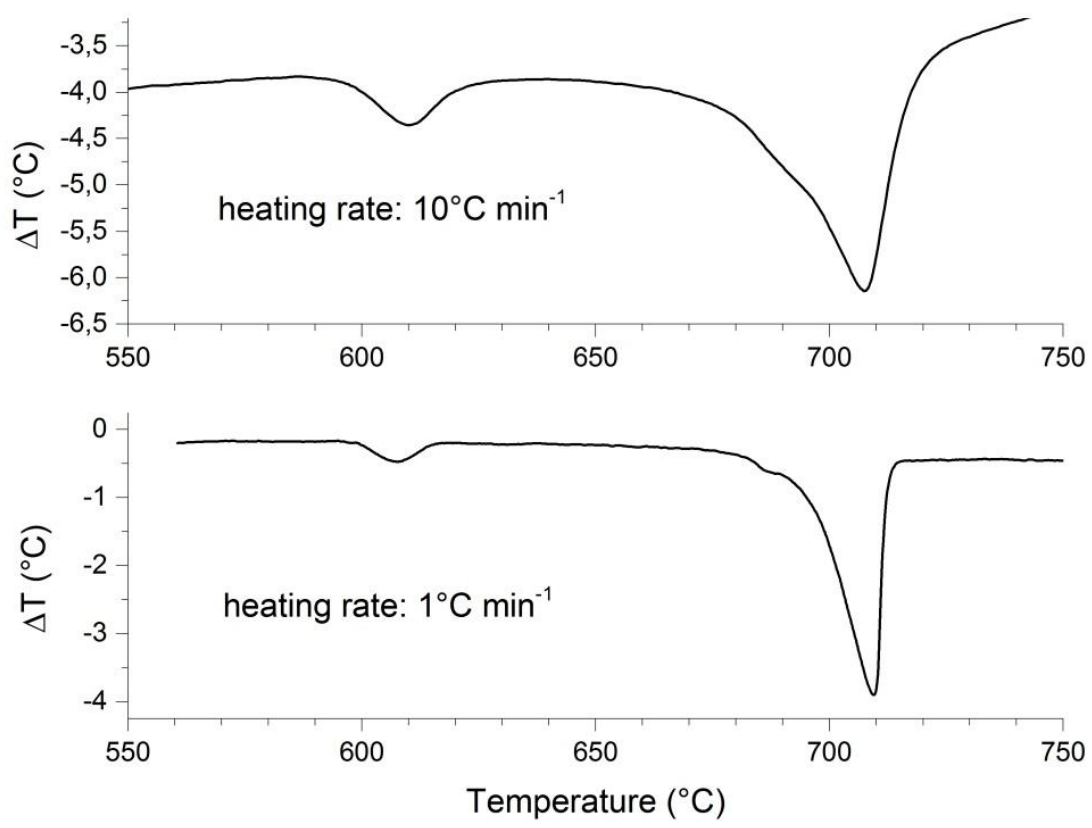

Fig. 6 - DTA traces of BZBO crushed fibers at 10 and $1^{\circ} \mathrm{Cmin}^{-1}$

As previously observed [10], an endothermic peak at $593{ }^{\circ} \mathrm{C}$ can be seen before the melting at $670{ }^{\circ} \mathrm{C}$. This thermal event could correspond to a phase transformation linked to the loss of boron oxide, loss undergoing a shift of the melt and crystal composition in the $\mathrm{Bi}_{2} \mathrm{O}_{3}-\mathrm{B}_{2} \mathrm{O}_{3^{-}}$ $\mathrm{ZnO}$ ternary system.Moreover, the melting peak consists of two overlapping endothermic peaks as shown by the DTA trace at $1^{\circ} \mathrm{C} \min ^{-1}$, the small first one between 680 and $690^{\circ} \mathrm{C}$ corresponding to a shoulder at $10^{\circ} \mathrm{C} \mathrm{min}^{-1}$. This is the sign of an incongruent melting behavior.

To confirm thehypothesis of phase transformations in the solid state, high temperature X-ray powder diffraction experiments were performed on crushed fibers between 590 and $680^{\circ} \mathrm{C}$.The experiments were limited to $680^{\circ} \mathrm{C}$ to avoid the appearance of liquid, detrimental to the achievement of usable X-ray diffractograms. The results are shown in Fig. 7. 


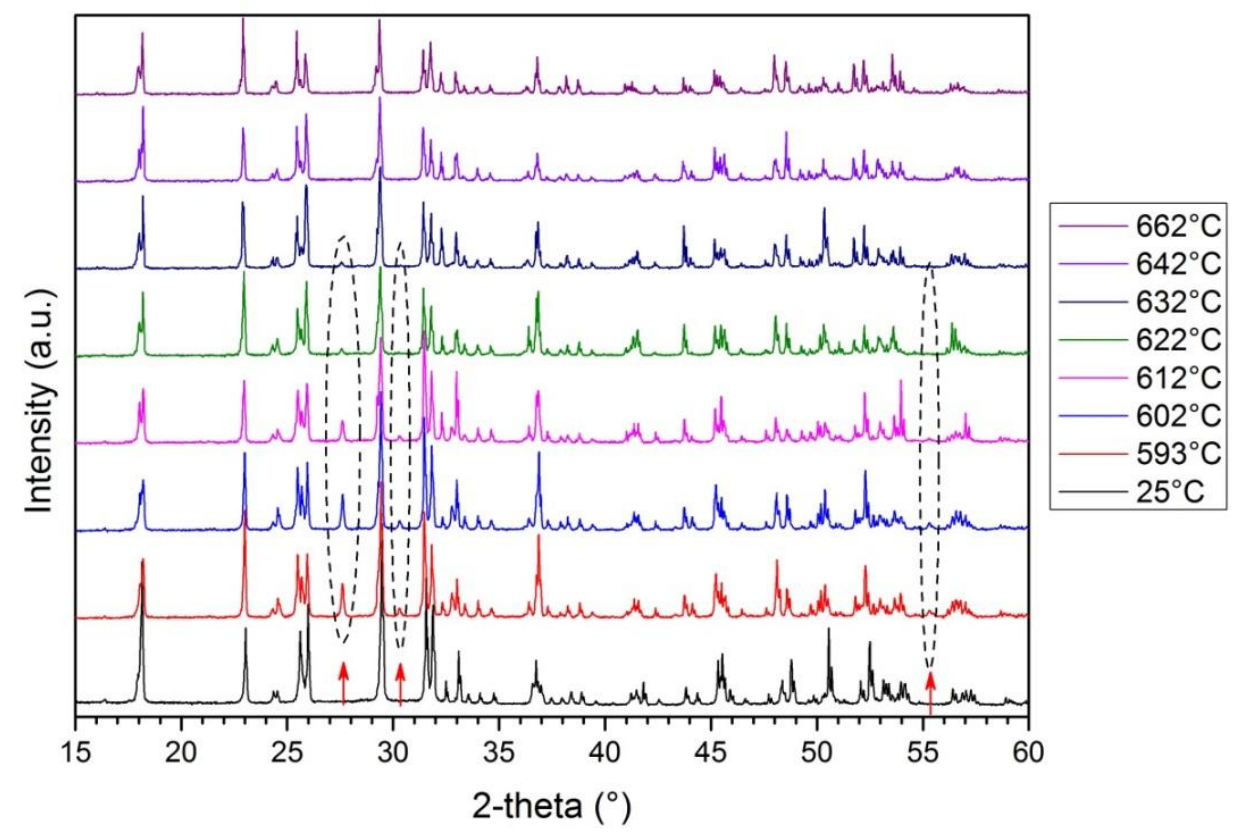

Fig. 7 - X-ray diffractograms of BZBO crushed fibers as a function of temperature (from bottom to top : $25,593,602,612,622,632,642$ and $662^{\circ} \mathrm{C}$ )

It can be seen that three extra peaks at $2 \theta=27.70^{\circ}, 31.0^{\circ}$ and $55.25^{\circ}$ can be observed. They appear at $593^{\circ} \mathrm{C}$ and disappear above $632^{\circ} \mathrm{C}$. The temperature corresponds closely to that of the first endothermic peak of Fig. 6. This confirms that a phase transformation in the solid state occurs at that temperature and is due to a composition shiftin the $\mathrm{Bi}_{2} \mathrm{O}_{3}-\mathrm{B}_{2} \mathrm{O}_{3}-\mathrm{ZnO}$ ternary system. The phase diagram of the ternary system being unknown, only assumptions can be made at this stage. Tentatively, the decreasing intensity of thesenew three diffraction peaks could be assigned to a change in the ratio of phases in equilibrium when temperature increases.A second endothermic peak would rationally be expectedat the exit of the corresponding equilibrium domain, but, as the amount of phase appeared at $593^{\circ} \mathrm{C}$ tends to strongly decrease when temperature increases, it is quite possible that the heat associated to this transformation is too small to be detected in our DTA experiments. Whatever may be, the other phenomena observed on heating strongly suggest an incongruentbehavior of the BZBO melting, possibly, of peritectic type. In these conditions, the crystal growth with too high 
pulling rates would undergo the co-crystallization of $\mathrm{BZBO}$ and a high temperature phase responsible of the color of fibers. Then, the obtention of pure BZBO crystals would require the use of low pulling rates to allow the completion of the invariant reaction. To validate that interpretation, attempts of growth at pulling rates as low as 1.2 and $0.15 \mathrm{mmh}^{-1}$ were made. At $1.2 \mathrm{~mm} \mathrm{~h}^{-1}$, the fibers obtained were still yellow colored. At $0.15 \mathrm{mmh}^{-1}$, a small transparent and colorless crystal, but with cracks, could be obtained after a pulling of about 17 hours (Fig. 8).The very small size of the crystal not allowing to polish it and examine it by SEM, it was extensively studied by confocal Raman spectroscopy. Fig. 9 shows typical spectra obtained at its surface and in its core for different positions along the crystal. The excitation wavelength was $633 \mathrm{~nm}$ which results in some intensity differences between the Raman bands and the spectra presented above.However, the chemical homogeneity and composition of this BZBO crystal is confirmed.

Attempts to grow longer fibers are in progress although they were unsuccessful until now as our fiber growth apparatus does not easily allow for stable growth over the long time period necessary.

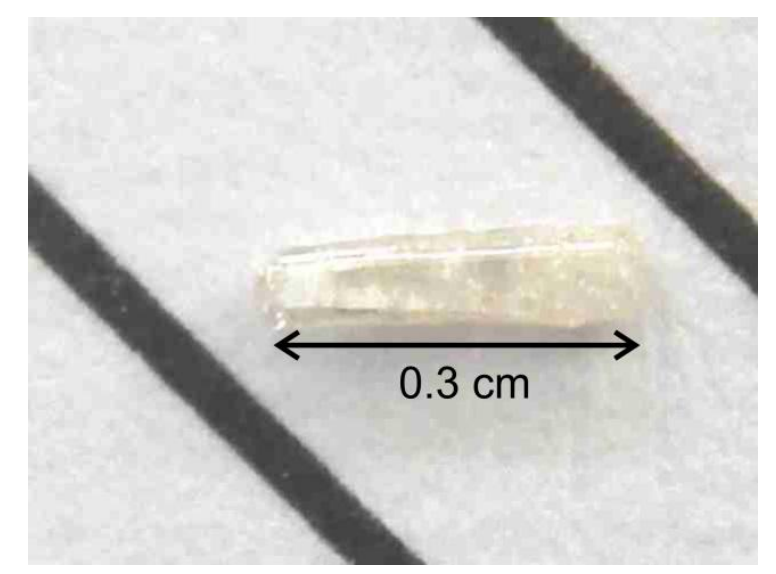

Fig. 8 - Colorless BZBO crystal fiber obtained with $0.15 \mathrm{mmh}^{-1}$ pulling rate 

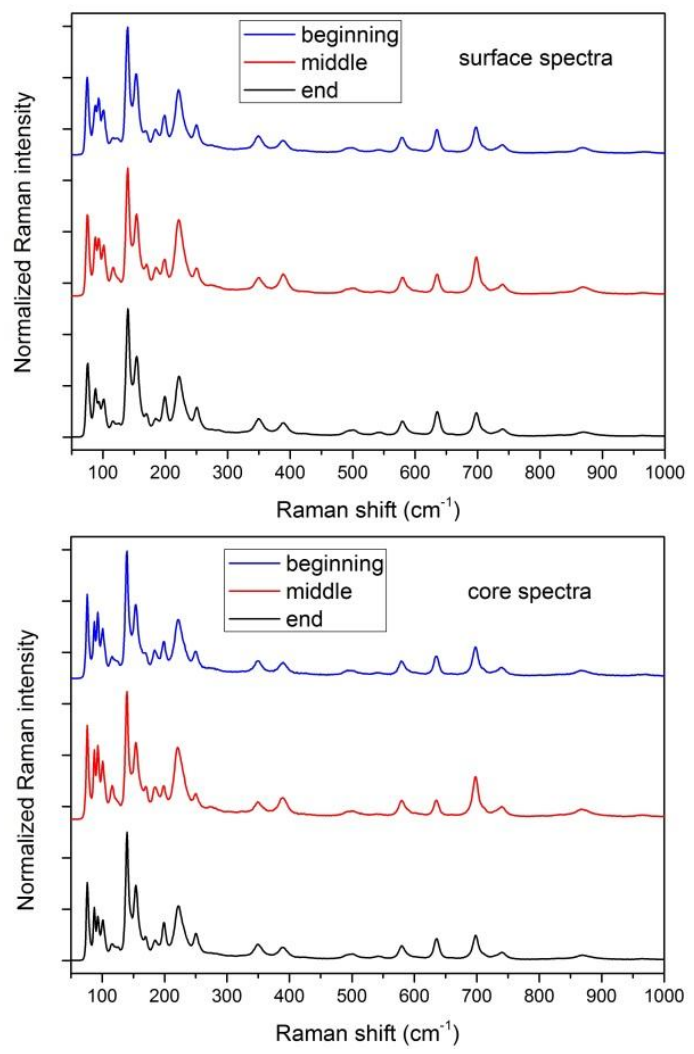

Fig. 9 - Typical Raman spectra of a BZBO crystal pulled at $0.15 \mathrm{~mm} \mathrm{~h}^{-1}$

\section{Conclusion}

A detailed study of the origin of colorin $\mathrm{Bi}_{2} \mathrm{ZnB}_{2} \mathrm{O}_{7}$ crystal fibers, grown by the micropulling down technique, has been done during this work. LHPG experiments have shown that the yellow/red color is not due to a reaction between the melt and the crucible as supposed earlier [10]. It would be the result of the loss by evaporation of a substantial amount of boron oxide from the melt leading to the displacement of the melt composition in the ternary system. At this point, the melt would have an incongruent behavior requiring very low pulling rates to obtain colorless fibers. Under these conditions, a small colorless BZBO crystal was obtained. The growth of longer fibers is now in progress to deeply investigate them. 


\section{Acknowledgments}

Elemental analyses were performed by CNRS Analysis Central Service (Villeurbanne, France). SEM investigations were carried out at Luxembourg Institute of Science and Technology (Belvaux, Luxembourg). High temperature XRD experiments were made at Jean Lamour Institute of the University of Lorraine (Nancy, France)

\section{References}

[1] S. Miao, Z. Xia, M.S. Molokeev, J. Zhang, Q. Liu, Crystal structure refinement and luminescence properties of blue-green emitting $\mathrm{CaSrAl}_{2} \mathrm{SiO}_{7}: \mathrm{Ce}^{3+}, \mathrm{Li}^{+}, \mathrm{Eu}^{3+}$ phosphors, $\mathrm{J}$. Mat. Chem. C 3 (2015) 8322-8328, http://dx.doi.org/10.1039/c5tc01629k

[2] I.P. Sahu, D.P. Bisen, N. Brahme, Luminescence properties of greenemitting $\mathrm{Ca}_{2} \mathrm{MgSi}_{2} \mathrm{O}_{7}: \mathrm{Eu}^{2+}$ phosphor by a solid-statereactionmethod, Luminescence, 30 (2015) 1125-1132, http://dx.doi.org/10.1002/bio.2869

[3] I.P. Sahu, D.P. Bisen, N. Brahme, Structural characterization and opticalproperties of $\mathrm{Ca}_{2} \mathrm{MgSi}_{2} \mathrm{O}_{7}: \mathrm{Eu}^{2+}, \mathrm{Dy}^{3+}$ phosphorby solid-state reactionmethod, Luminescence, 30 (2015) 526532, http://dx.doi.org/10.1002/bio. 2771

[4]Q. Zhang,J. Wang, M. Zhang, W. Ding, Q. Su, Luminescence properties of $\mathrm{Sm}^{3+}$ doped $\mathrm{Bi}_{2} \mathrm{ZnB}_{2} \mathrm{O}_{7}$, J. Rare Earth 24 (2006) 392-395, http://dx.doi.org/10.1016/S1002$\underline{0721(06) 60130-0}$

[5] Q. Zhang, J. Wang, H. Ni, L. Wang, Synthesis and luminescent properties of $\operatorname{Ln}^{3+}\left(\operatorname{Ln}^{3+}=\right.$ $\left.\mathrm{Eu}^{3+}, \quad \mathrm{Dy}^{3+}\right) \quad$ dopedBi $2 \mathrm{ZnB}_{2} \mathrm{O}_{7}$ phosphors, $\quad$ Rare Metals $31 \quad$ (2012) 35-38, http://dx.doi.org/10.1007/s12598-012-0458-y

[6] J. Barbier, N. Penin, L.M. Cranswick, Melilite-type borates $\mathrm{Bi}_{2} \mathrm{ZnB}_{2} \mathrm{O}_{7}$ and $\mathrm{CaBiGaB}_{2} \mathrm{O}_{7}$, Chem. Mater. 17 (2005) 3130-3136, http://dx.doi.org/10.1021/cm0503073

[7] F. Li, S. Pan, Crystal growth and nonlinear optical coefficients of $\mathrm{Bi}_{2} \mathrm{ZnOB}_{2} \mathrm{O}_{6}$, J. Cryst. Growth 318 (2011) 629-631, http://dx.doi.org/10.1016/j.jcrysgro.2010.10.065 
[8] F. Li, S. Pan, X. Hou, J. Yao, A novelnonlinearopticalcrystal $\mathrm{Bi}_{2} \mathrm{ZnOB}_{2} \mathrm{O}_{6}$, Cryst. Growth Des. 9 (2009) 4091-4095, http://dx.doi.org/10.1021/cg900336r

[9] N. Li, P. Fu, Y. Wu, J. Zhang, Growth, thermal and opticalproperties of a new nonlinearopticalcrystal: $\quad \mathrm{ZnBi}_{2} \mathrm{~B}_{2} \mathrm{O}_{7}$, J. Cryst. Growth 311 (2009) 3476-3478, http://dx.doi.org/10.1016/j.jcrysgro.2009.04.016

[10] N. Kozhaya, M. Ferriol, M. Cochez, M. Aillerie, Growth and characterization of bismuth zinc borate $\mathrm{Bi}_{2} \mathrm{ZnB}_{2} \mathrm{O}_{7}$ crystalfibersby the micro-pulling down technique, J. Cryst. Growth 364 (2013) 51-56, http://dx.doi.org/10.1016/j.jcrysgro.2012.11.059

[11] R.S. Feigelson, The laser-heated pedestal growth method: apowerful tool in the search for new high performance laser crystals, Springer Ser. Opt. Sci. 47 (1985) 129-142, http://dx.doi.org/10.1007/978-3-540-39236-1_19

[12] R.S. Feigelson, Pullingopticalfibers, J. Cryst. Growth 79 (1986) 669-680, http://dx.doi.org/10.1016/0022-0248(86)90535-X 